\title{
Toward an integration of research on employee voice
}

\author{
Adrian Wilkinson ${ }^{\mathrm{a}, *}$, Michael Barry ${ }^{\mathrm{a}}$, Elizabeth Morrison ${ }^{\mathrm{b}}$ \\ ${ }^{\text {a }}$ Griffith University, Brisbane, Australia \\ ${ }^{\mathrm{b}}$ Stern University, New York City, NY, USA
}

\section{Introduction}

Employee voice refers to all of the ways and means through which employees attempt to have a say about, and influence, their work and the functioning of their organization (Bashshur \& Oc, 2015; Wilkinson, Dundon, Donaghey, \& Freeman, 2014; Morrison, 2014). Voice can cover a range of different domains and topics (e.g. working conditions, compensation, policies and procedures, work methods) and can occur through a variety of mechanisms: formal and informal, direct and indirect, individual and collective. Employee voice is a topic of central interest to scholars in human resource management (HRM), industrial relations (IR), and organizational behaviour (OB).

However, these research disciplines diverge quite significantly in how they conceptualize and study voice, and the research on voice remains largely within self-contained siloes (Kaufman, 2015; Pohler \& Luchak, 2014a, 2014b; Wilkinson \& Fay, 2011). This lack of integration is particularly apparent between the fields of IR and OB, and unfortunately, it impedes progress toward comprehensive understanding of employee voice and appreciation of its different purposes, dimensions and manifestations. OB scholars, for example, have an interest in understanding what motivates individual employees to speak up when they have opinions, concerns, workrelevant information, ideas or suggestions. The predominant view of voice in OB is that it is a discretionary behaviour that, while challenging the status quo, is aimed at bringing about constructive change for the organization or the work unit, even if current management might disagree (Detert \& Burris, 2007; Morrison, 2014; Tangirala \& Ramanujam, 2012). Important in OB is how receptive leaders are to employee voicing, as workers interpret signals from managers and these signals condition future voice behaviours. In $\mathrm{OB}$ research, there is an underlying assumption that employees generally want to speak up, because there are issues that they care about, and that management should value this voice because of its potential benefits for organizational performance and the potential risks of not addressing important issues or considering different viewpoints. The focus is on the micro-level factors that encourage or discourage voice, and voice is generally portrayed as an individual-level, discretionary, proactive behaviour (Morrison, 2014; Van Dyne \& LePine, 1998).

In contrast, IR scholars see voice as the expression of worker interests that are separate and distinct from those of the firm, and as a vehicle for employee self-determination (Budd, 2004, Kaufman, 2015; Wilkinson, Donaghey, Dundon \& Freeman, 2014). Employees seek voice to have some level of say in decisions that have a material impact on what they do in the workplace, and to assert and protect their interests, which are seen to be in tension with those of management. Gordon (1988), for example, argued that employees have the moral right as owners of their labour to express their views about the conditions under which they labour. Organizations, however, have strong conforming pressures that act to suppress free speech and opposing viewpoints. As a result of this struggle for control, extra-organizational voice mechanisms are necessary to protect the rights of individuals to express themselves, such as unions and whistleblowing provisions. Formal institutions, such as trade unions, collective bargaining, arbitration, works councils and grievance procedures, feature prominently in IR research, and are viewed as important in facilitating genuine employee voice.

The HRM literature draws from both of these traditions, and like IR, has broadened the notion of voice away from a single channel of worker representation (i.e. unions), to include other mechanisms for employees to express their interests. HRM scholars have also

\footnotetext{
* Corresponding author at: Centre for Work, Organisation and Wellbeing (WOW), Griffith University, Nathan, QLD, 4111, Business 3 (N63) Room 1.11, Australia.

E-mail address: adrian.wilkinson@griffith.edu.au (A. Wilkinson).
} 
linked employee voice to the broad concept of employee engagement (Marchington, 2008), and to efforts by employers to introduce high performance work practices (e.g., Harley, 2014). According to McCabe and Lewin (1992), voice consists of two elements: first, the expression of complaints or grievances through unions and devices such as tribunals or arbitration, the second, participation of employees in the decision-making processes of the organization, through mechanisms such as semi-autonomous teams.

Within each of these three disciplines, there has been keen interest in understanding employee voice. However, IR, HR and OB scholars have tended to advance the study of employee voice along divergent conceptual pathways, and researchers have not generally looked across disciplinary boundaries. OB studies have largely excluded research from IR from their discussions of voice because IR looks mainly at formal structures allowing for collective level voice rather than the more informal individual-level behaviour of speaking up at work (Morrison, 2011). Likewise, IR has excluded from consideration the informal face-to-face ways in which employees might express their concerns and ideas to their managers, and has tended to assume that the interests of these two parties are necessarily at odds.

The aim of this special issue is not just to explore the different ways of conceptualizing employee voice, but also to highlight what might be gained from integrating across these different disciplinary perspectives. A number of voice scholars have begun to acknowledge the problems with a siloed approach to the study of voice, and there is an emerging recognition of the need for more integration across disciplines (Bashur \& Oc, 2014; Brinsfield, 2014; Mowbray, Wilkinson, \& Tse, 2015; Knoll, Wegge, Unterrainer, Silva, \& Jønsson, 2016). It is with that in mind that we required contributors to this special issue to draw from multiple perspectives with an eye toward building a broader, cross-disciplinary understanding of employee voice.

\section{Voice silos}

Despite the fact that employee voice has been an important topic across a wide range of disciplines, including industrial and labour relations, human resource management, organizational behaviour, economics, and law, these different disciplines have applied strikingly different conceptual lenses and hold vastly different assumptions about the meaning and purpose of voice (Pohler \& Luchak, 2014a, 2014b). In a very real sense, the fields are using the term to refer to quite different things. An unfortunate by-product of these different approaches has been a failure to accept and appreciate what other disciplines have to offer, or to consider other ways of understanding employee voice.

In particular, IR scholars have been quite critical of how voice is conceptualized and studied within OB. Specifically, they have criticized the $\mathrm{OB}$ voice literature for diverging from the historical roots of the employee voice concept by largely ignoring mechanisms of employee representation (e.g. unions) as vehicles for voice (Kaufman, 2015) and for focusing on just individual-level discretionary voice behaviour. The OB literature has also been criticized for defining voice in a way that reflects the interests of management (Barry \& Wilkinson, 2015), and for failing to consider how the interests of management and employees are not aligned. Indeed, OB voice scholars have focused far more on situations where input from employees can be organizationally helpful, while giving much less attention to situations where employees are voicing to exert their own legitimate interests which may be at odds with the interests of their organization. It is also fair to say that OB voice researchers have largely ignored research coming from IR and HRM, and have not been particularly interested in the role of formal voice mechanisms or institutional structures in enabling or stifling voice.

Yet parochialism exists on both sides. As Barry and Wilkinson (2015) argued, IR voice researchers have been preoccupied with examining structures and mechanisms that enable voice, and have shown less regard for understanding the relational aspects of voice that are prominent in OB. By and large, IR researchers have not been very interested in what the OB literature has to offer, or in appreciating how that literature has provided insight into the choice of whether or not to speak up with one's concerns, ideas and opinions.

Such a large gulf has emerged between these literatures that research produced in one field is generally unread and uncited by researchers in the other, despite both examining the same fundamental question as to why and how employees do or do not speak up in the workplace. It is as if researchers in one field feel they will learn nothing from the work developed in another, and thus they continue to cite, build from, and write for, separate research communities, which serves to perpetuate disciplinary blind spots and potentially narrow taken-for-granted assumptions about the meaning and role of employee voice.

\section{How the literatures differ}

As a number of writers have noted, IR and OB voice research share a common intellectual foundation in Hirschman's (1970) seminal exit, voice and loyalty framework (Bashshur \& Oc, 2014; Brinsfield, 2014; Mowbray et al., 2015). Hirschman saw voice as a political process, whereby customers speak up and express their dissatisfaction in response to organizational decline. As Hirschman saw it, voice is an alternative to exit, which is a process of withdrawing from an economic exchange rather than raising concerns in the hope of improving an unsatisfactory situation. Voice was defined as an attempt to change rather than escape from an objectionable state of affairs. This definition of voice was subsequently extended to apply not just to customers but also to employees (Farrell, 1983; Withey \& Cooper, 1989).

The IR literature has largely adhered to this conceptualization, focusing on voice as a means of expressing grievances and pushing for better working conditions. The OB voice literature, however, took a divergent path, starting with an influential paper by Van Dyne and LePine (1998). Building from research on extra-role behaviours, these authors used the term voice to capture discretionary behaviour that is challenging yet "promotive." That is, they conceptualized it as a behaviour that challenges the status quo and is change oriented, yet with an intent to be constructive: making things better for the work unit, the organization, other employees, or 
Table 1

Key differences between IR and OB conceptualizations of voice.

\begin{tabular}{lll}
\hline & Voice in IR & Voice in OB \\
\hline Primary level of analysis & Collective & Individual \\
Primary focus of analysis & Voice structures and systems & Voice as a behavioral act \\
Primary means through which voice occurs & Formal mechanisms & Informal interactions \\
Primary enablers/inhibitors & Structural & Both individual and contextual \\
Types of employees & Workers, both unionized and non-unionized & All, including professionals and mid-to-high level managers \\
Types of input being voiced & Worker interests, grievances & Suggestions, ideas, opinions, information about problems \\
Assumptions about motives & Expressive or corrective; self- interest & Promotive or improvement-oriented; self plus other interest \\
Assumptions about employment relationship & Adversarial & Largely non-adversarial \\
Assumptions about interests & Conflicting & Largely aligned \\
Assumptions about who controls voice & Management & Employees \\
Why voice is important & Protecting workers; promoting workplace & Improving organizational effectiveness; preventing or \\
& democracy & correcting problems \\
Alternative to voice & Exit & Silence
\end{tabular}

customers. This view of voice has become widely adopted within OB. Although OB voice researchers do consider speaking up about problems, concerns, unfairness and mistreatment as forms of voice (Morrison, 2014; Van Dyne, Ang, \& Botero, 2003), and while there have been a number of recent studies on "prohibitive voice," defined as expressions of concern about work practices, incidents, or harmful behaviour (Liang, Farh, \& Farh, 2012), the predominant focus has been on speaking up with ideas and suggestions for improvement, or what has been called "promotive voice" (Liang et al., 2012). Moreover, while participative decision making, grievance behaviour, and whistleblowing are important topics within the field of OB more broadly, these are generally treated as distinct from voice. In sum, the $\mathrm{OB}$ voice literature has moved significantly away from Hirschman's original definition, with the notion of voice being a response to an objectionable state of affairs being largely absent.

It is instructive to consider the IR and OB conceptualizations of voice side by side. In doing so, a number of key differences come to light. These differences are summarized in Table 1. To begin, in ER, voice research focuses on collective-level structures and systems that allow for employee input, and voice is viewed as occurring via formal mechanisms such as unions, works councils, etc. In contrast, within $\mathrm{OB}$, the focus is on the individual-level behavioral act of speaking up, and voice is viewed as occurring via informal interactions with supervisors and co-workers. Given these different perspectives, it is not surprizing that research in IR has emphasized the structural enablers and inhibitors to voice, whereas OB research has focused on identifying individual-level (e.g. attitudes, perceptions) and micro-level contextual (e.g. supervisor behaviour, team climate) enablers and inhibitors. A core idea in OB is that employees often feel that their input is not wanted or that speaking up is personally risky.

The two literatures have also focused on different types of employees, as well as different types of input being conveyed (or not) by those employees. Given its historical roots, IR is interested in non-managerial and generally low-skilled employees at the bottom of the organizational power hierarchy, and the means by which such employees can communicate their interests and grievances to management. $\mathrm{OB}$, on the other hand, is interested in employees more broadly defined, including managers and professionals, and their proclivity to communicate ideas, suggestions, viewpoints, and information about workplace issues and processes. While OB does include speaking up with "concerns" as an important form of voice, this idea is less central than it is in IR.

The underlying assumptions in the two literatures, both implicit and explicit, are also quite different. IR researchers assume that the employment relationship is largely adversarial, with conflicting interests between workers and management. They also assume the motive for voice to be both expressive and corrective - driven by the employees' own interests, regardless of what this means for the organization. In contrast, OB researchers view the employment relationship as largely non-adversarial, with interests that are largely aligned. They also assume the motives for voice to be promotive and/or improvement oriented. Through the lens of OB, employees are cast as acting on interests that go beyond the self. Employees who voice are assumed to be doing so not just to vent or complain, but to bring about constructive change (Van Dyne \& LePine, 1998).

There are three other key differences worth pointing out. One, the IR literature assumes that voice is largely controlled by management, whereas the OB literature sees employees as more in control of the decision of whether, when, and how to speak up. Two, and importantly, scholars in the two disciplines care about voice for very different reasons. For IR, voice is about protecting workers and promoting workplace democracy. It is political and relates to the inherent imbalance of power between workers and management. For OB, voice is about improving organizational or team effectiveness, broadly defined, and preventing or correcting problems. This can range from offering a suggestion for making the workplace more environmentally friendly, to highlighting a practice that creates gender bias and needs to be changed, to expressing a dissenting point of view on a particular decision. Three, following from Hirschman's framework, IR views exit as the main alternative to voice. OB, on the other hand, view silence as the main alternative to voice, and does not give much consideration to exit.

\section{Steps toward integration}

Despite these significant differences, we remain hopeful that there can be greater integration of voice research, and that this Special Issue is a movement in that direction. While there have been a number of reviews of employee voice that take steps toward integration (Bashshur \& Oc, 2014; Klaas, Olson-Buchanan, \& Ward, 2012; Morrison, 2011, 2014), none of these reviews have 
developed a research agenda that points to how voice scholarship can be more fully integrated across disciplines. There is, however, some recent evidence suggesting a shift toward a broader, inter-disciplinary view of voice. For example, Mowbray et al. (2015:383) offered the hopeful view that "it is possible that there are more similarities between the HRM/IR and OB conceptualization of voice than previously documented." Brinsfield (2014: 128) urged that "OB scholars such as himself "need to stay abreast of relevant new research from a wide variety of sources. We also need to thoughtfully question our paradigmatic assumptions surrounding voice and silence which may unwittingly constrain our thinking." Maynes and Podsakoff (2014:87-88) also noted that that "the narrow focus of past $[\mathrm{OB}]$ research may have precluded investigation into other types of voice." Their objective was to "develop a new, more expansive voice behaviour framework" that includes both self and other-interested motives as well as behaviour that might be destructive to the organization. It is worth noting, however, that Maynes and Podsakoff (2014) did not cite any papers on voice from the IR or HRM literatures, and do not consider the expression of grievances, collective behaviours or representative structures within their broader conception of voice.

One path toward integration might be to recognize that there are differences in levels of analysis to the phenomenon of voice. Voice occurs, is influenced by, and can be examined at the societal (macro) level, the organizational or departmental (meso) level, and the individual (micro) level (see Kwon, Farndale, \& Park, 2016). The macro level consists of the regulatory framework, which determines organizational policy around voice. It is at this level that we see a dominance of IR scholars who examine state support and other institutional mechanisms which vary between countries and regions (Barry, Wilkinson, \& Gollan, 2014). The meso level, where much HRM research takes place, relates to the voice systems that organizations establish and the extent to which these are utilised in practice. In contrast, at the micro level, the field of OB examines the individual-level motivators and inhibitors to voice, such as dispositions, attitudes and perceptions, emotions and beliefs (Morrison, 2014; Wilkinson, Gollan, Kalfa, \& Xu, 2018). Voice systems are the focus of the first two levels whereas voice behaviour is the focus of the third. Rather than being contradictory, these different levels of analysis are complementary, and a full understanding of voice can only come about via a perspective that takes each of them into account. Thus, we see potential opportunity in a model of voice that spans across and connects the various levels of analysis.

Another path toward integration might be to more explicitly recognize that IR and OB look at different types of employees and different types of voice messages. As noted, IR is interested mainly in lower-status workers and the communication of grievances and worker interests. OB has focused on a broader set of employees, including managers and professionals, and communication of ideas, suggestions, and concerns about workplace dynamics and processes. Thus, it might be fruitful for voice researchers to consider the boundary conditions of each perspective, and where those boundaries can be broken down and where they need to be maintained. For example, there may be some factors that help to explain voice regardless of the type of employee or what they are voicing about, and other factors that apply just to certain classes of workers or issues. It is worth considering where there is a need or opportunity for integration, and where there are important differences that need to be taken into account.

Cross-disciplinary integration might also be facilitated by a closer connection between the OB voice and silence literatures. OB scholars who write about silence recognize and accept that there are strong "inhibiting" factors surrounding employee non-voicing (Pinder \& Harlos, 2001). Organizations can create deeply ingrained climates of silence (Morrison \& Milliken, 2003), with such climates effectively suppressing the opportunity to speak up. This idea resonates strongly with the argument in IR that management may systematically limit the terms over which employees can voice (Donaghey, Cullinane, Dundon, \& Wilkinson, 2011). Moreover, the OB silence literature explicitly incorporates group and organizational norms within the silence construct. Through processes of social cognition, group norms can develop and become entrenched about what issues are on and off the table (Morrison, WheelerSmith \& Kamdar, 2011; Milliken, Morrison, \& Hewlin, 2003). This notion relates to the core idea in IR that voice (or lack thereof) is largely a collective-level phenomenon heavily influenced by contextual forces. Thus, we suggest that stronger links between the silence and voice literatures within OB has the potential to facilitate bridge-building to IR and HRM.

Lastly, there is an opportunity for voice scholars, across disciplines, to come together with the aim of creating voice opportunities for all workers (Adler, 2016; Kochan et al., 2019), including temps, part-timers, independent contractors, unpaid interns, and people who work in the informal economy. Such non-traditional workers have been largely neglected in the voice literature, even though in 2017 the U.S. Bureau of Labour Statistics reported 10.6 million independent contractors (6.9\% of total employment). We would encourage OB scholars to consider how the motivators and outcomes of voice might be different for non-traditional workers, and what this might suggest for designing effective voice mechanisms. Similarly, we would encourage IR and HRM scholars to examine appropriate structures for non-traditional workers to have voice, in light of the barriers they may face such as low status and isolation from other workers. In this pursuit, researchers might be able to learn something from practice. For example, Uber drivers have set up their own online groups to facilitate voice. Interestingly, these workers are not only concerned about traditional IR issues such as working conditions and pay, but are also sharing suggestions useful for the company, such as better placement of markers for airports pickups. (Kaine, Walker, \& Josserand, 2018).

\section{The special issue}

The papers appearing in this Special Issue are from scholars who, like the three editors, approach employee voice from different backgrounds and assumptions. Their papers draw from a range of disciplines and literature streams and offer a rich set of insights. We briefly summarize the papers below.

Engemann and Scott examine voice behaviour in the setting of high risk, safety-oriented organizations. In doing so, they extend the traditional, hierarchical approach to understanding the impact of social context on voice, offering a framework that considers the importance of a range of different types of social support, and the role of collective mindfulness. Focused on specific and identifiable 
policies and practices, the hierarchical social context reflects formal and top-down features of an organization's approach to safety behaviour and voice. Yet supervisors and peers also play an important role in managing safety, as they bear some capacity for influencing the extent to which safety is understood and subordinated to other strategic goals, and the extent to which voice is supported. Engemann and Scott focus on how the nature of voice behaviour in safety-oriented organizations is informed both by cues from different levels of the organizational hierarchy as well as from sustained mindful organizing. Their framework highlights that a significant feature of the work environment in safety-oriented organizations is ambiguity, and that voice should be viewed as a communicative reaction to that ambiguity.

Kwon and Farndale point out that while employee voice may have positive outcomes for organizations, the effectiveness of encouraging employees to speak out is not guaranteed unless employees perceive voice as safe and effective. They offer a multi-level framework, focused on how organizations norms regarding different types of voice channels signal to employees the extent to which those channels are safe and effective. Kwon and Farndale also argue that, at the macro-level, national culture shapes an organization's norms regarding different voice channels. Extending beyond past research, they explore the impact of several distinct cultural values: power distance, uncertainty avoidance, collectivism, performance orientation, assertiveness, and tightness-looseness. A core argument that they put forward is that these dimensions of national culture interact with organizational voice norms to signal to employees the safety and efficacy of different types of voice.

Nechanska et al. highlighthow Organizational Behaviour (OB), Industrial Relations (IR) and Labour Process (LP) approach the phenomena of employee voice from diverse ontological anchor points. This paper aims to advance a broader conceptual framework of voice and silence based on the inter-disciplinary integration of OB, IR and LP perspectives. The framework advances a critical pluralist view of employee silence by drawing on the concept of 'structured antagonism'. The approach captures how voice and silence reflect a relationship shaped by an unequal power exchange. The integrated framework aims to enable HRM scholars to connect different contextual levels, layers and dimensions of employee silence to paint a 'fuller picture' of why employees do not speak-up and to build a critical pluralist perspective on voice and silence across diverse workplaces.

\section{References}

Adler, P. S. (2016). Alternative Economic Futures: A Research Agenda for Progressive Management Scholarship. Vol. 30, Academy of Management Perspectives123-128. Barry, M., \& Wilkinson, A. (2015). Pro-social or pro management: A critique of the conception of employee voice as a pro-social behaviour within organisational behaviour. British Journal of Industrial Relations. https://doi.org/10.1111/bjir.12114.

Barry, M., Wilkinson, A., \& Gollan, P. (2014). Voices from around the globe. In A. Wilkinson, G. Wood, \& R. Deeg (Eds.). The Oxford Handbook of Employment Relations: Comparative Employment Systems. Oxford: Oxford University Press.

Bashshur, M. R., \& Oc, B. (2014). When voice matters: A multilevel review of the impact of voice in organizations. Journal of Management, 41, 1530-1554.

Bashshur, M. R., \& Oc, B. (2015). When voice matters A multilevel review of the impact of voice in organizations. Journal of Management, 41(5), 1530-1554.

Brinsfield, C. (2014). Employee voice and silence in organizational behaviour. In A. Wilkinson, J. Donaghey, T. Dundon, \& R. Freeman (Eds.). Handbook of Research on Employee Voice. Edward Elgar.

Budd, J. (2004). Employment with a Human Face: Balancing Efficiency, Equity and Voice. Ithaca: ILRPress.

Detert, J. R., \& Burris, E. R. (2007). Leadership behavior and employee voice: Is the door really open? Academy of Management Journal, 50(4), 869-884.

Donaghey, J., Cullinane, N., Dundon, T., \& Wilkinson, A. (2011). Re-conceptualising employee silence: problems and prognosis. Work, Employment and Society, 51-67.

Farrell, D. (1983). Exit, voice, loyalty, and neglect as responses to job dissatisfaction: A multidimensional scaling study. Academy of Management Journal, $26,596-607$.

Gordon, W. L. (1988). Range of employee voice. Employee Responsibilities and Rights, 1, 283-299.

Harley, B. (2014). High performance work systems and employee voice. In A. Wilkinson, J. Donaghey, T. Dundon, \& R. Freeman (Eds.). Handbook of Research on Employee Voice. Edward Elgar.

Hirschman, A. O. E. (1970). Voice and Loyalty: Responses to Decline in Firms, Organizations and States. Cambridge, MA, USA: Harvard University Press.

Kaine, S., Walker, M., \& Josserand, E. (2018). Working in the Disrupted Economy (Transcripts). University of Technology Sydneyhttps://doi.org/10.26195/ 5bbed3090abea.

Kaufman, B. (2015). Theorising determinants of employee voice: An integrative model across disciplines and levels of analysis. Human Resource Management Journal, 25(1), 19-40.

Klaas, B., Olson-Buchanan, J., \& Ward, A.-K. (2012). The determinants of alternative forms of workplace voice: An integrative perspective. Journal of Management, 38(1), 314-345.

Knoll, M., Wegge, J., Unterrainer, C., Silva, S., \& Jønsson, T. (2016). Is our knowledge on voice and silence growing in organizations? Building bridges and (re) discovering opportunities. German Journal of Human Resource Management, 30, 161-194.

Kochan T et al (2019) Voice Gaps at work, Options for closing Them, and challenges for Future Actions and Research ILR review.

Kwon, B., Farndale, E., \& Park, J. G. (2016). Employee voice and work engagement: Macro, meso, and micro-level drivers of convergence? Human Resource Management Review, 26(4), 327-337.

Liang, J., Farh, C. I., \& Farh, J. L. (2012). Psychological antecedents of promotive and prohibitive voice: A two-wave examination. Academy of Management Journal, 55, 71-92.

Marchington, M. (2008). Employee voice systems. In P. Boxall, J. Purcell, \& P. Wright (Eds.). The Oxford Handbook of Human Resource Management. Oxford: Oxford University Press.

Maynes, T. D., \& Podsakoff, P. M. (2014). Speaking more broadly: An examination of the nature, antecedents, and consequences of an expanded set of employee voice behaviors. Journal of Applied Psychology, 99, 87-112.

McCabe, D., \& Lewin, D. (1992). Employee voice: A human resource management perspective. California Management Review, 34(3), 112-123.

Milliken, F. J., Morrison, E. W., \& Hewlin, P. F. (2003). An exploratory study of employee silence: Issues that employees don't communicate upward and why. Journal of Management Studies, 40(6), 1453-1476.

Morrison, E. (2011). Employee voice behavior: Integration and directions for future research. Academy of Management Annals, 5, $373-412$.

Morrison, E. (2014). Employee voice and silence Annual Review of Organizational Psychology \&amp; Organizational Behavior. 1(1), 173-197.

Morrison, E. W., Wheeler-Smith, S. L., \& Kamdar, D. (2011). Speaking up in Groups: A Coeds-Level Study of Group Voice. Journal of Applied Psychology, 96, 183-191.

Morrison, E., \& Milliken, F. (2003). Speaking up, remaining silent: The dynamics of voice and silence in organizations. Journal of Management Studies, 40(6), $1353-1358$.

Mowbray, P., Wilkinson, A., \& Tse, H. (2015). An integrative review of employee voice: Identifying the common conceptualisation and research agenda. International Journal of Management Reviews, 17, 382-400.

Pinder, C. C., \& Harlos, K. P. (2001). Employee silence: Quiescence and acquiescence as responses to perceived injustice. Research in Personnel and Human Resources Management, 20, 331-369. 
Pohler, D. M., \& Luchak, A. A. (2014a). Balancing efficiency, equity and voice: The impact of unions and high involvement work practices on work outcomes. Industrial \& Labor Relations Review, 67, 1-32.

Pohler, D., \& Luchak, A. (2014b). The missing employee in employee voice research. In A. Wilkinson, J. Donaghey, T. Dundon, \& R. Freeman (Eds.). The Handbook of Research on Employee Voice (pp. 188-207). Edward Elgar.

Tangirala, S., \& Ramanujam, R. (2012). Ask and you shall hear (but not always): Examining the relationship between manager consultation and employee voice. Personnel Psychology, 65(2), 251-282.

Van Dyne, L., Ang, S., \& Botero, I. C. (2003). Conceptualizing employee silence and employee voice as multidimensional constructs. Journal of Management Studies, 40(6), 1359-1392.

Van Dyne, L., \& LePine, J. A. (1998). Helping and voice extra-role behaviors: Evidence of construct and predictive validity. Academy of Management Journal, 41(1), 10. Wilkinson, A., Donaghey, J., Dundon, T., \& Freeman, R. (Eds.). (2014). The Handbook of Research on Employee Voice. Elgar Press.

Wilkinson, A., Dundon, T., Donaghey, J., \& Freeman, R. (2014). Employee voice: Charting new terrain. In A. Wilkinson, J. Donaghey, T. Dundon, \& R. Freeman (Eds.). The Handbook of Research on Employee Voice. Elgar Press.

Wilkinson, A., \& Fay, C. (2011). New times for employee voice? Human Resource Management, 50(1), 65-74.

Wilkinson, A., Gollan, P., Kalfa, S., \& Xu, Y. (2018). Voices unheard: Employee voice in the new century. The International Journal of Human Resource Management, 2018.

Withey, M., \& Cooper, W. (1989). Predicting exit, voice, loyalty, and neglect. Administrative Science Quarterly, 34(4), 521-539. 